\title{
Implantation of computed tomography-guided lodine-125 seeds in combination with chemotherapy for the treatment of stage III non-small cell lung cancer
}

\author{
Xiaodong Huo, MD', , Bin Huo, MD', , Huixing Wang, MD 2,3, Lei Wang, MD!, Qiang Cao, PT', Guangjun Zheng, MD4, \\ Junjie Wang, MD5, Shude Chai, MD4, Zuncheng Zhang, MD6, Kuo Yang, MD², Yuanjie Niu, MD, PhD², \\ Haitao Wang, MD, PhDl,2 \\ 'Department of Oncology, The Second Hospital of Tianjin Medical University, Tianjin, ${ }^{2}$ Central Laboratory/Tianjin Research Institute \\ of Urology, The Second Hospital of Tianjin Medical University, Tianjin, ${ }^{3}$ Pain Management Center, The Second Hospital of Tianjin Medical \\ University, Tianjin, ${ }^{4}$ Department of Thoracic Surgery. The Second Hospital of Tianjin Medical University, Tianjin, ${ }^{5}$ Department of Radiation \\ Oncology, The Third Hospital Peking University, Beijing, 'Department of Nuclear Medicine, The Second Hospital of Tianjin Medical University, \\ Tianjin, R.P. China
}

\begin{abstract}
Purpose: We investigated the role of computed tomography (CT)-guided Iodine- 125 ( $\left.{ }^{125} \mathrm{I}\right)$ seed implantation in combination with chemotherapy for the treatment of stage III non-small cell lung carcinoma (NSCLC).

Material and methods: The data from 182 patients with stage III NSCLC who were treated with radioactive ${ }^{125} \mathrm{I}$ seed implantation between June 2002 and June 2009, and who received sequential platinum-based combination chemotherapy using the most common combination of platinum and gemcitabine, were retrospectively reviewed. The 182 patients received a prescribed dose of $110.0 \mathrm{~Gy}$, with a median radioactivity of $0.70 \mathrm{mCi}$ (range, $0.64-0.78 \mathrm{mCi}, 2.37-$ $3.26 \times 107 \mathrm{~Bq}$ ). The median number of ${ }^{125}$ I seeds was 38 pellets (range, 6-105 pellets). The median post-operation dose covering $100 \%$ of the target volume $\left(\mathrm{D}_{100}\right)$ was $94.5 \mathrm{~Gy}$ (range, 54.6-125.5 Gy). The median $\mathrm{D}_{90}$ was $143.0 \mathrm{~Gy}$ (range, 121.6-184.0).

Results: The 1-, 3-, and 5-year overall survival rates were $83.35 \%, 25.57 \%$, and $11.34 \%$, respectively; the median survival time was 24.76 months. At 1, 3, and 5 years, the local control rates were $92.01 \%, 86.51 \%$, and $76.45 \%$, respectively; the median local control time was 25.28 months. For patients with stage IIIA and IIIB NSCLC, the median survival times were 26.67 and 24.59 months, respectively $(p=0.2)$. Pre-treatment hemoglobin level, tumor volume, and postoperative $\mathrm{D}_{100}$ were significantly associated with survival. A total of 24 patients experienced pneumothorax (incidence rate, $13.20 \%$ ), and 17 patients experienced hemothorax (incidence rate, $5.0 \%$ ).

Conclusions: CT-guided ${ }^{125}$ I seed implantation combined with chemotherapy is an effective, minimally invasive method for the treatment of stage III NSCLC. Furthermore, hemoglobin levels before treatment, $\mathrm{D}_{100}$, and the maximum diameter of the tumor may be prognostic factors in patients with NSCLC treated sequentially with radiotherapy and chemotherapy.

Key words: ${ }^{125} \mathrm{I}$, lung cancer, non-small cell lung carcinoma (NSCLC).

\section{Purpose}

Approximately, $80 \%$ of all lung cancers are non-small cell carcinomas. For these tumors, a complete surgical resection still yields the best treatment results. However, only $25 \%$ of all patients are candidates for surgical treatment [1]. Nearly $45 \%$ of patients with non-small cell lung carcinoma (NSCLC) have stage III disease [2]. The treatment outcomes of these patients are unsatisfactory due to mediastinum lymph node metastasis, or the presence of a large surgical excision range, which may lead to a high post-operative residual tumor volume and a high risk of recurrence. The management of these patients who are unfit for surgery remains controversial, although many are treated with radiation therapy [3]. Establishment of radiation guidelines for the management of these patients is crucial for several reasons. Notably, improvements in medical care and technology are expected to increase the 
mean life expectancy, resulting in doubling the number of people older than 65 years living with lung cancer by $2050[4,5]$.

Implantation of radioactive Iodine- $125\left({ }^{125} \mathrm{I}\right)$ seeds is a treatment option with a history of over 100 years. Early on, it was adopted for prostatic cancer, followed by the treatment of pancreatic cancer, lung cancer, intracranial tumors, and pharyngeal cancer $[6,7,8]$. Developments in ultrasound, computed tomography (CT), and treatment planning systems (TPS) have also helped to improve the treatment. The technology of implanting radioactive ${ }^{125} \mathrm{I}$ seeds for prostate cancer continues to develop $[9,10,11]$. However, the type and regimen of radiation therapy used for this patient category is undefined, as no randomized trials comparing different regimens are available [3,12,13]. At present, the use of external beam radiotherapy is the standard of care.

Table 1. Patient characteristics $(n=182)$

\begin{tabular}{|c|c|c|}
\hline Factor & No. of patients & Percentage (\%) \\
\hline \multicolumn{3}{|l|}{ Gender } \\
\hline Male & 104 & 57.1 \\
\hline Female & 78 & 42.9 \\
\hline Median age & $68(39-87)$ & \\
\hline \multicolumn{3}{|l|}{$\begin{array}{l}\text { KPS score before } \\
\text { treatment }\end{array}$} \\
\hline$\geq 80$ & 128 & 70.3 \\
\hline$<80$ & 54 & 29.7 \\
\hline \multicolumn{3}{|l|}{$\begin{array}{l}\text { Smoking index (pack } \\
{[20 \text { cigarettes])/year }}\end{array}$} \\
\hline$<80$ & 65 & 35.7 \\
\hline$\geq 80$ & 117 & 64.3 \\
\hline \multicolumn{3}{|l|}{ Tumor site } \\
\hline Central type & 91 & 50.0 \\
\hline Peripheral type & 91 & 50.0 \\
\hline \multicolumn{3}{|c|}{ Diameter of tumors (cm) } \\
\hline$<3.0$ & 54 & 29.7 \\
\hline $3.0-5.0$ & 71 & 39.0 \\
\hline $5.1-7.0$ & 57 & 31.3 \\
\hline \multicolumn{3}{|l|}{ Primary tumor stage } \\
\hline Stage IIIA & 26 & 14.3 \\
\hline Stage IIIB & 156 & 85.7 \\
\hline \multicolumn{3}{|l|}{ Tumor pathology } \\
\hline $\begin{array}{l}\text { Squamous cell } \\
\text { carcinoma }\end{array}$ & 113 & 62.1 \\
\hline Adenocarcinoma & 62 & 34.1 \\
\hline Other & 7 & 3.8 \\
\hline \multicolumn{3}{|l|}{ N stage } \\
\hline NO & 0 & 0 \\
\hline $\mathrm{N} 1$ & 26 & 14.3 \\
\hline N2 & 81 & 44.5 \\
\hline N3 & 75 & 41.2 \\
\hline
\end{tabular}

KPS - Karnofsky performance status scale
CT-guided implantation of radioactive ${ }^{125} \mathrm{I}$ seeds is an effective and feasible method for the treatment of lung cancer [14]. In the current study, a total of 182 patients with stage III NSCLC treated with CT-guided, ${ }^{125}$ I brachytherapy between June 2002 and June 2009 were retrospectively analyzed to evaluate the clinical effect and prognostic factors associated with this intervention.

\section{Material and methods}

\section{Characteristics of the patients}

In this retrospective study, patients with histologically confirmed NSCLC, without lung metastasis and with documented inoperable NSCLC stage III disease, were selected (Table 1). Other enrollment criteria included age $\geq 18$ years and an estimated individual life expectancy of $\geq 6$ months. Moreover, patients were required to have sufficient remaining lung function (forced expiratory volume in 1 second, $\mathrm{FEV}_{1} \geq 1.5 \mathrm{l} / \mathrm{s}$, or $\geq 50 \%$ of the respective individual normal value), as well as a Karnofsky performance score $\geq 70 \%$. Additionally, adequate hematological, hepatic, and renal function was essential for inclusion in the trial (white blood cell, WBC $\geq 3 \times 10^{9} / 1$ ). According to these criteria, our study population consisted of 182 patients who were admitted to our hospital from June 2005 to June 2011. Informed consent was obtained from the subjects, and the study was approved by the Ethics Committee of our hospital. There were 104 men and 78 women, ranging in age from 39 to 87 years (mean, $68 \pm 9$ years). Patient Karnofsky scores as recorded upon admission and progress notes were as follows: 128 cases ranged between $80-100$, and 54 cases ranged between 60-70. A total of 88 patients had central-type lung cancer, while the remaining 94 patients had peripheral-type lung cancer. Prior to the study, all patients were informed about the procedure and its possible treated, with a combined therapy with platinum and gemcitabine, for a median of 3 cycles (range, 1-6 cycles). Chemotherapy was given 1 week after the seeds implantation.

\section{${ }^{125}$ I seed sources}

The ${ }^{125}$ I seed sources were the 6,711 type (Seeds Biological Pharmacy Ltd., Tianjin, China), and preserved by sealing in airtight containers. The core source was silver containing ${ }^{125} \mathrm{I}$ packaged with a titanium alloy tube sealed by laser. The seeds had a radioactive half-life of 59.6 days, with a mean radioactivity of $0.70 \mathrm{mCi}$ (range, $0.64-0.78 \mathrm{mCi}, 2.37-3.26 \times 10^{7} \mathrm{~Bq}$ ). The ${ }^{125} \mathrm{I}$ seed source air specific kinetic energy was $0.945 \mu \mathrm{Gy} \times \mathrm{m}^{2} / \mathrm{h}$ (range, $0.847-1.018 \mu \mathrm{Gy} \times \mathrm{m}^{2} / \mathrm{h}$ ). The activity of the CDX-2000A well-type ionization chamber was measured. Each seed source was $4.5 \mathrm{~mm}$ in length and $0.8 \mathrm{~mm}$ in diameter, and was sterilized using high-temperature sterilization.

\section{Implantation equipment}

All implantation equipment was made in China, including the calibrating equipment and the tion needle (Hakko Co., Ltd.,1490 O-aza lsobe, Chikuma-Shi, Nagano, Japan) was sterilized and sealed. 


\section{Other equipment}

The prowess TPS (Prowess Panther 3D SSGI, Chico, CA, USA), and a multilayer spiral CT (GE Lightspeed 64, General Electric Company, Fairfield, CT, USA) with a slice thickness of $5.0 \mathrm{~mm}$ were used. CT scan parameters: tube voltage of $120 \mathrm{kV}$, the tube current of $100 \mathrm{mAs}$, the field of view to cover the tumor range. TG- 43 formalism was applied, as well as corrections used in dosimetry.

\section{${ }^{125}$ I seed implantation}

Patients with stage III NSCLC had CT scans performed to determine their puncture location (Figure 1A). After disinfecting the skin surface of the surgical area and administering local anesthesia, an attempt was made to puncture the center of the tumor. Next, using the CT scanner again, the calibrating equipment was put into place. At this point, punctures were made along the intercostal space, at $1.0 \mathrm{~cm}$ intervals to a depth of $0.5 \mathrm{~cm}$ below the edge of the tumor. The CT scanner was used again to confirm location accuracy, followed by implantation of seeds, using the implanting device and keeping equal distance between the seeds (range, 1.0-1.5 cm) (Figure 1B and C). The total number of seeds to be implanted in each tumor was calculated using the TPS before implantation.

\section{Response evaluation criteria}

Local response was evaluated in accordance with RECIST (Response Evaluation Criteria in Solid Tumors) [15] at 6 months after implantation, which is defined as the following: 1) complete remission (CR), the complete regression of the treated tumor mass (confirmation at 4 weeks of treatment or later); 2) partial remission (PR) or the reduction in the sum of the largest tumor diameters by at least $30 \%$ (confirmation at 4 weeks of treatment or later);3) progressive disease (PD), or increase in the sum of the largest tumor diameters by $20 \%$; 4) stable disease (SD), indicating neither PR nor PD.

\section{Statistical analysis}

Statistical analyses were performed using the Statistical Package for Social Sciences software (SPSS), version 13.0 (IBM Corp., Armonk, NY, USA). The survival rate of patients was determined by Kaplan-Meier analysis, and differences in survival rates among groups were compared by the log-rank test. Univariate variables with statistical significance entered the multivariate analysis. Multivariate analysis was conducted using the Cox regression modeling. $P<0.05$ was considered as statistically significant.
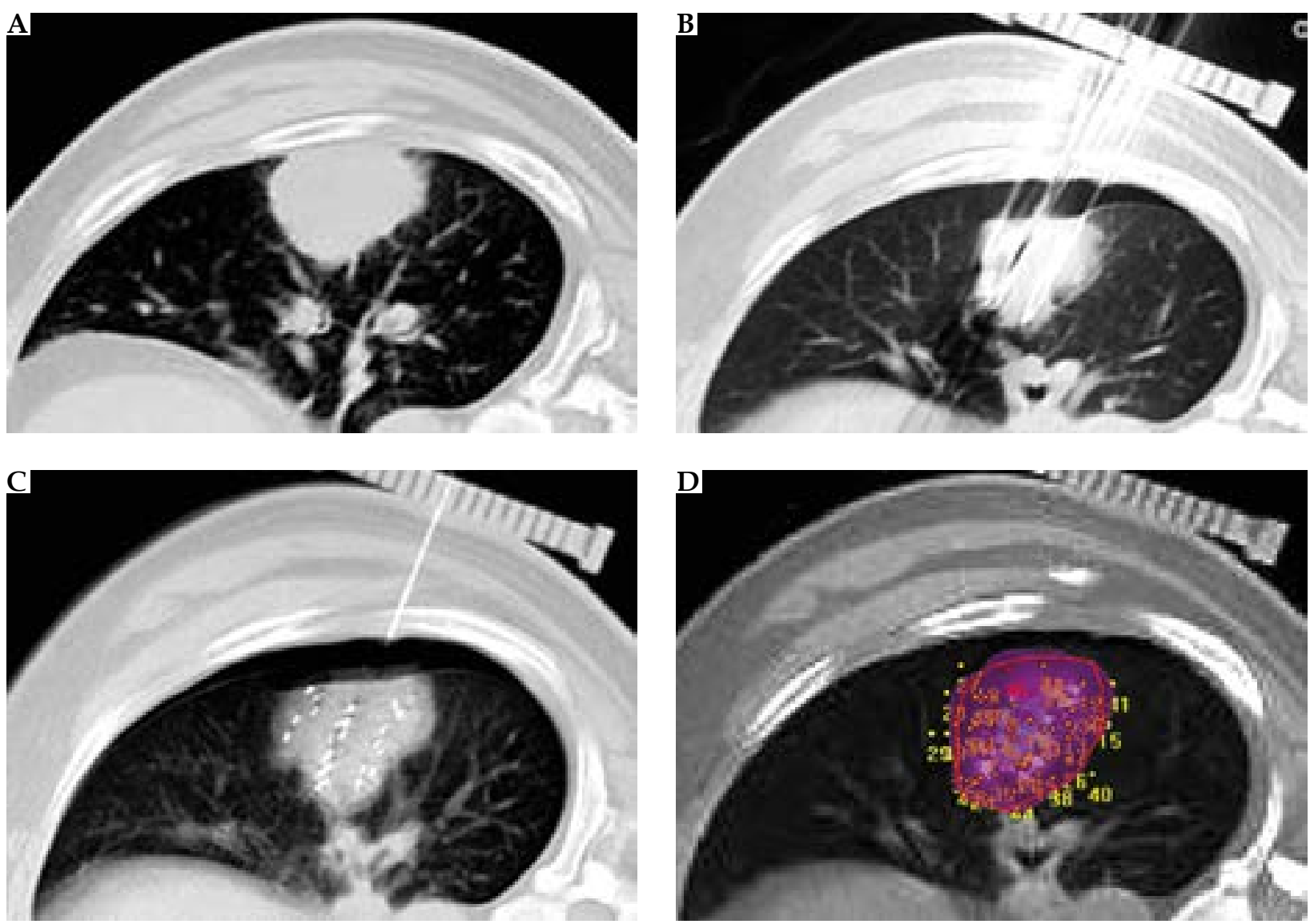

Fig. 1. A) Pre-operative computed tomography (CT) showed lesions located in the right lung. B) Intraoperative CT shows that the needle is inserted. C) Post-operative imaging, with the needle out, showing pneumothorax. D) Post-operative quality authentication: two-dimensional graph of planar implantation and dose distribution on treatment planning system (TPS) 

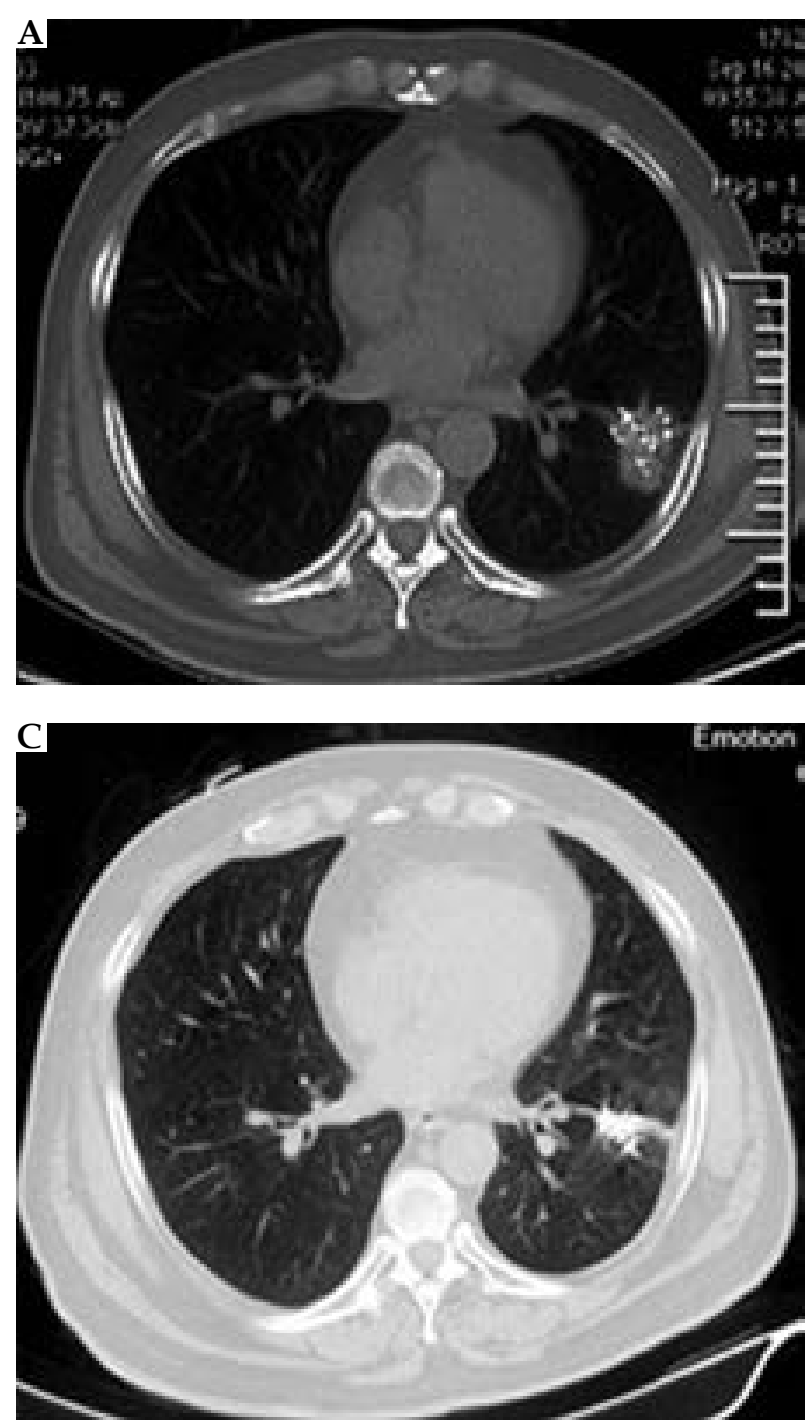

\section{Results}

\section{Post-surgery verification of quality}

The information on seeds from CT input was transferred to the TPS to verify quality, which was then exported as dose-volume histograms (DVHs). The 182 patients received a prescribed dose of $110.0 \mathrm{~Gy}$. The median number of ${ }^{125} \mathrm{I}$ seeds was 38 (range, 6-105). The median post-operative dose covering $100 \%$ of the target volume

Table 2. Therapeutic efficacy of the implantation of radioactive ${ }^{125}$ I seeds for 182 patients at the 6-month follow-up $[n(\%)]$

\begin{tabular}{lcccc} 
Stage & CR & PR & SD & PD \\
\hline III A, 26 (14) & $10(38)$ & $16(62)$ & $0(0)$ & $0(0)$ \\
\hline III B, 156 (86) & $19(12)$ & $125(80)$ & $8(5)$ & $4(3)$ \\
\hline In all, 182 (100) & $29(16)$ & $141(90)$ & $8(4)$ & $4(2)$
\end{tabular}

$C R$-complete remission, $P R$ - partial remission, $P D$ - progressive disease, $S D$ - stable disease

$C R+P R$ of patients with stage III A NSCLC is higher than that of patients with III B NSCLC (100\%: 92\% $\times 2=3.38 ; p=0.000)$

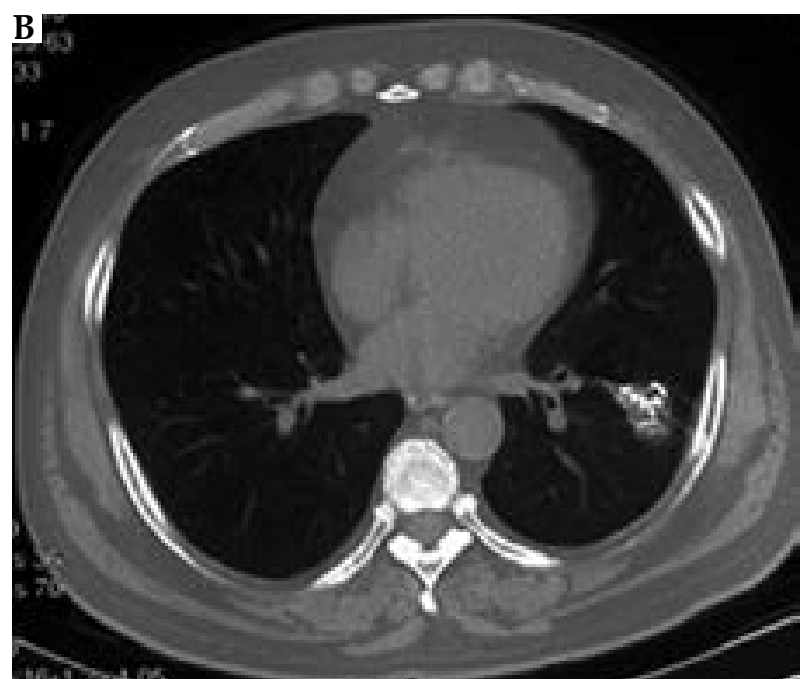

Fig. 2. A) One month after brachytherapy, an applicator is accurately inserted into the tumor to implant ${ }^{125} \mathrm{I}$ seeds. B) Six months after brachytherapy, the tumor is significantly reduced, with well distributed radioactive seeds remaining. C) Two years after brachytherapy, tumor has disappeared, with only well distributed radioactive seeds remaining

$\left(\mathrm{D}_{100}\right)$ was $94.5 \mathrm{~Gy}$ (range, 54.6-125.5 Gy), and the median $\mathrm{D}_{90}$ was $143.0 \mathrm{~Gy}$ (range, 121.6-184.0 Gy).

\section{Short-term therapeutic efficacy}

The median follow-up of all patients was 23 months (range, 7.0-80 months). Compared with pretreatment, CT images obtained at the 6-month (Figure 2) follow-up revealed that 29 of 182 patients were in complete remission, while 141 were in partial remission. In our study, the total effective rate $(\mathrm{CR}+\mathrm{PR})$ for patients who received implantation of radioactive ${ }^{125}$ I seeds was $93.4 \%$ (Table 2 ).

\section{Long-term survival analysis}

The 1-, 3-, and 5-year overall survival (OS) rates were $83.35 \%, 25.57 \%$, and $11.34 \%$, respectively, and the local control rates were $92.01 \%, 86.51 \%$, and $76.45 \%$, respectively (Figure $3 \mathrm{~A}$ and B). The median survival time was 24.76 months, and the median local control time was 39.2 months. For stage IIIA and IIIB patients, the median survival times were 26.67 and 24.59 months, respectively (Table 3). 

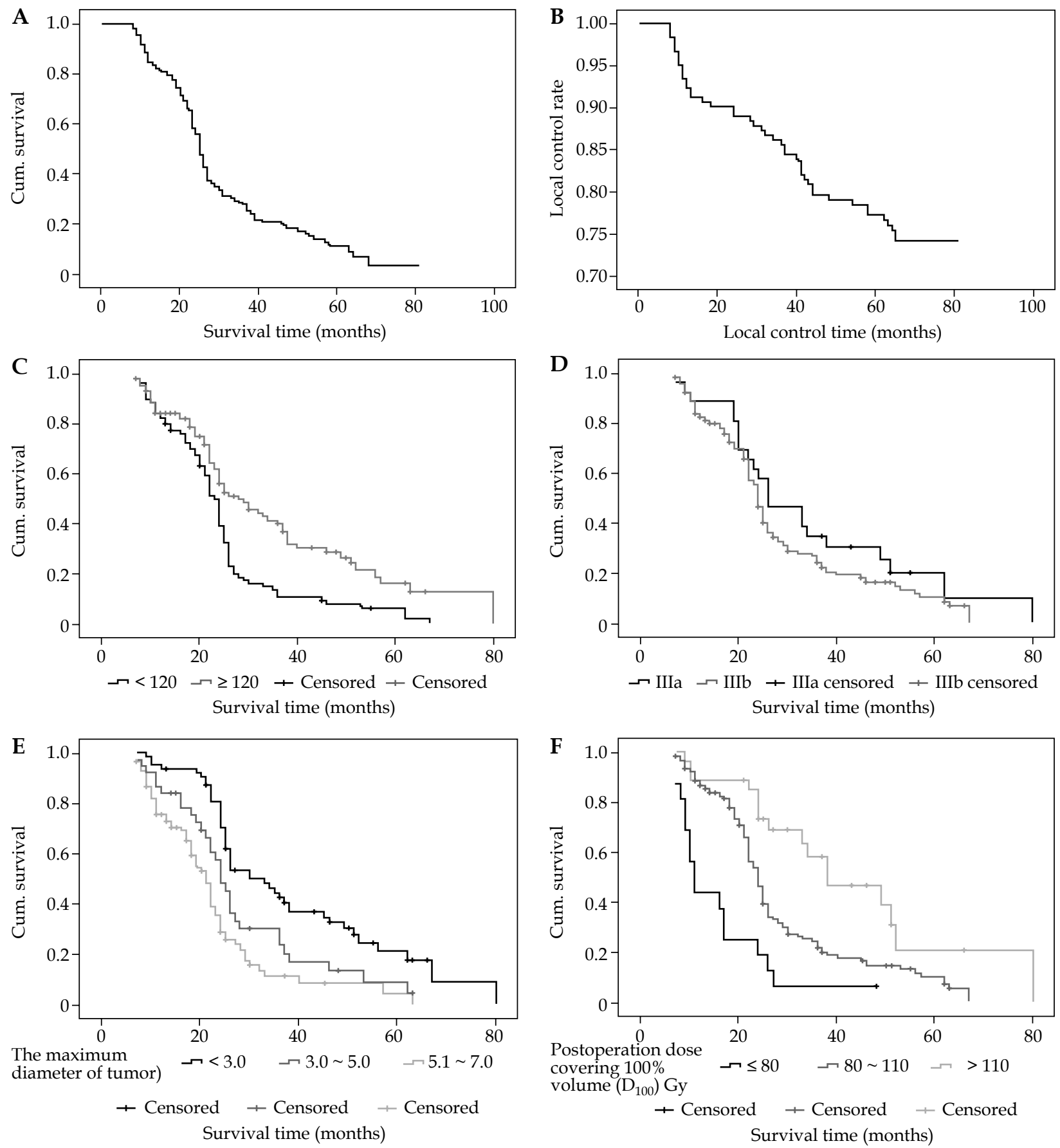

Fig. 3. A) Kaplan-Meier estimate data show overall survival for all patients after ${ }^{125}$ I seed implantation. B) Kaplan-Meier estimate data show the local control rate for all patients after ${ }^{125}$ I seed implantation. C) Overall survival according to pretreatment hemoglobin (g/l). D) Overall survival according to clinical stages. E) Overall survival according to the diameter of tumors (cm). F) Overall survival according to the D100 after treatment (Gy)

\section{Univariate analysis of survival}

Univariate analysis showed that several factors were associated with survival: pretreatment hemoglobin, using a cut-off point of $120 \mathrm{~g} / \mathrm{l}$, smoking index or using the number of 'pack years' ( 1 pack year $=20$ cigarettes $/$ day for 1 year), tumor diameter $(\mathrm{cm})$, tumor $(\mathrm{T})$ stage, and $\mathrm{D}_{100}$ (Gy) (Table 3). There were statistically significant single factor variables in the multivariate COX regres- sion analysis including the following: hemoglobin before treatment $(\mathrm{g} / \mathrm{l})$, smoking index, diameter of tumors $(\mathrm{cm})$, T stage, and $\mathrm{D}_{100}$ after treatment (Gy).

\section{Multivariate Cox regression analysis}

The multivariate Cox regression analysis showed that several factors were associated with survival (Table 4). Pre-treatment hemoglobin, using a cut-off point of $120 \mathrm{~g} / \mathrm{l}$, 
Table 3. Univariate analysis of survival of 182 patients with stage III non-small cell lung carcinoma

\begin{tabular}{|c|c|c|c|c|c|c|c|}
\hline Factors & & $n$ & $\begin{array}{c}\text { 1-year } \\
\text { survival rate (\%) }\end{array}$ & $\begin{array}{c}\text { 3-year } \\
\text { survival rate (\%) }\end{array}$ & $\begin{array}{c}5 \text {-year } \\
\text { survival rate (\%) }\end{array}$ & $\chi^{2}$ & $p$ \\
\hline \multirow[t]{2}{*}{ Hemoglobin before treatment $(\mathrm{g} / \mathrm{l})$} & $<120$ & 80 & 82.50 & 10.77 & 6.28 & \multirow[t]{2}{*}{13.022} & \multirow[t]{2}{*}{0.000} \\
\hline & $\geq 120$ & 102 & 84.08 & 37.02 & 12.94 & & \\
\hline \multirow{2}{*}{$\begin{array}{l}\text { Smoking index } \\
\text { (pack [20 cigarettes])/year }\end{array}$} & $<80$ & 83 & 95.20 & 37.15 & 18.73 & \multirow[t]{2}{*}{4.016} & \multirow[t]{2}{*}{0.048} \\
\hline & $\geq 80$ & 99 & 82.37 & 24.61 & 8.31 & & \\
\hline \multirow[t]{3}{*}{ Diameter of tumors $(\mathrm{cm})$} & $<3.0$ & 62 & 93.54 & 42.64 & 17.50 & \multirow[t]{3}{*}{27.449} & \multirow[t]{3}{*}{0.000} \\
\hline & $3.0-5.0$ & 37 & 83.78 & 23.45 & 4.47 & & \\
\hline & $5.1-7.0$ & 83 & 72.93 & 11.19 & 0 & & \\
\hline \multirow[t]{2}{*}{ T stages } & $\mathrm{T} 1+\mathrm{T} 2$ & 27 & 96.30 & 38.23 & 19.66 & \multirow[t]{2}{*}{4.366} & \multirow[t]{2}{*}{0.037} \\
\hline & $\mathrm{T} 3+\mathrm{T} 4$ & 155 & 81.10 & 23.53 & 7.98 & & \\
\hline \multirow[t]{3}{*}{$\mathrm{D}_{100}$ after treatment (Gy) } & $\leq 80$ & 16 & 43.75 & 6.25 & 0.00 & \multirow[t]{3}{*}{25.052} & \multirow[t]{3}{*}{0.000} \\
\hline & 80-110 & 139 & 86.90 & 21.65 & 7.29 & & \\
\hline & $>110$ & 27 & 88.89 & 46.60 & 20.7 & & \\
\hline
\end{tabular}

$D_{100}$ - dose covering $100 \%$ of the target volume

Table 4. Multivariate analysis of survival of 182 patients with stage III non-small cell lung carcinoma

\begin{tabular}{lccccccc} 
Influencing factor & $\begin{array}{c}\text { Regression } \\
\text { coefficient }\end{array}$ & $\begin{array}{c}\text { Standard } \\
\text { error }\end{array}$ & Wald & $p$ & OR & \multicolumn{2}{c}{$95 \% \mathrm{Cl}$} \\
\cline { 5 - 8 } & & & & Lower limit & Superior limit \\
\hline Hemoglobin before treatment $(\mathrm{g} / \mathrm{l})$ & 0.674 & 0.382 & 6.268 & 0.021 & 1.773 & 1.287 & 3.169 \\
\hline $\mathrm{D}_{100}$ after treatment $(\mathrm{Gy})$ & 0.923 & 0.239 & 11.310 & 0.000 & 2.643 & 1.504 & 3.835 \\
\hline Diameter of tumors $(\mathrm{cm})$ & 0.749 & 0.273 & 17.068 & 0.000 & 2.276 & 1.088 & 3.493
\end{tabular}

$D_{100}$-dose covering $100 \%$ of the target volume

was correlated with survival (Figure 3C). Tumor stage (IIIA vs. IIIB) did not have statistical significance (Figure 3D). Tumor diameter was a significant predictor for OS $(p<0.001)$, with patients having a tumor size $<3.0 \mathrm{~cm}$ for recurring tumors demonstrating better survival $(p=0.007)$. The median survival time was 41.03 months in patients with a tumor size $<3.0 \mathrm{~cm}$, and was 21.45 months in those with tumors $>3.0 \mathrm{~cm}$. Patients with tumors $<3.0 \mathrm{~cm}$ had a relatively higher CR rate $(71.85 \%, 23 / 32)$ compared with patients with a tumor size $>3.0 \mathrm{~cm}(28.15 \%, 9 / 32)$ (Figure 3E). The median survival time was 37.23 months in patients with $\mathrm{D}_{100}$ after treatment (Gy) < 80 Gy, 23.56 months in patients with $\mathrm{D}_{100}$ after treatment (Gy) 80-110 Gy, and 17.32 months in those with $\mathrm{D}_{100}$ after treatment (Gy) > 80 Gy (Figure 3F).

\section{Complications}

\section{Pneumothorax}

A total of 24 patients experienced pneumothorax, with an incidence rate of $13.2 \%$. According to the Common Terminology Criteria for Adverse Events (CTCAE) v. 4.0, 20 patients had grade 1 adverse reaction and 4 had grade 2 adverse reactions. Among the 24 patients, the intraoperative suction in 9 patients improved their status, while in the remaining 15 patients, the thoracic cavity was closed for drainage.

\section{Hemothorax}

A total of 17 patients experienced hemothorax, with an incidence rate of $5.0 \%$. According to the CTCAE, 15 patients had grade 1 adverse reaction and 2 had grade 2 adverse reactions; however, these symptoms disappeared 3 days after treatment with hemostatic drugs.

\section{Shifting and falling}

Six patients encountered shifting and falling of radioactive ${ }^{125}$ I seeds. In 4 patients, hemoptysis ejected 2 seeds, while in the other 2 patients, the seeds migrated into normal lung tissue or soft tissues during withdrawal of the needles. Soft tissue mainly refers to the chest wall muscles. The patients did not show any symptoms, and therefore did not receive clinical treatment.

\section{Fever}

Twenty-two patients experienced fever; the temperature in all cases was below $38.5^{\circ} \mathrm{C}$. Fever patients were given antipyretic drug treatment. Furthermore, 14 patients experienced grade 1 toxicity events, while 8 experienced grade 2 toxicity events; however, their symptoms disappeared after 1 day of treatment for these symptoms.

\section{Leukopenia}

A total of 49 patients experienced leukopenia, which occurred 1-2 weeks after chemotherapy; the primary cause was bone marrow suppression after chemotherapy. Among these, 31 patients experienced grade 1 toxicity events, while 18 patients experienced grade 2 toxicity events. Their white blood cell counts recovered after treatment with granulocyte-macrophage colony stimulating factor (GM-CSF). 


\section{Death}

There were 128 deaths through to the last day of follow-up (incidence rate, $70.3 \%$ ). Among these, 63 patients died due to cachexia, 31 due to pulmonary infection, 20 due to multiple organ failure, 12 due to brain metastasis, and 2 due to acute myocardial infarction.

\section{Discussion}

Radiation therapy is an important approach for oncotherapy. According to the statistics of International Union Against Cancer (UICC), 70\% of all patients with cancer need radiation therapy for a permanent cure or as an alleviative treatment [16]. Rafael et al. [17] have suggested that CT-guided percutaneous implantation of radioactive ${ }^{125} \mathrm{I}$ seeds is an effective treatment for patients with medically inoperable stage I NSCLC. Due to lack of early diagnosis, $75 \%$ of lung cancer patients present with an advanced stage of disease and cannot undergo resection. Implantation of radioactive ${ }^{125} \mathrm{I}$ seeds could be a new palliative treatment for a majority of patients with inoperable stage III NSCLC. In the last 20 years, a model of radio-chemotherapy has primarily evolved for the treatment of locally advanced NSCLC.

For unresectable stage IIIA patients, standard treatment may include either a sequential or concurrent combination of chemotherapy and radiation therapy (chemoradiation), and external radiation therapy for patients who cannot be treated with combined therapy. Several clinical investigations showed that the radical surgery in stage IIIA patients with bulky primary tumors may provide up to $50 \%$ increase in the 5 -year survival rate as compared to patients with incomplete resection [18]. Stage IIIB NSCLC represents about $17.6 \%$ of all lung cancers [19], with a 5-year survival rate of $3 \%$ to $7 \%$ [20].

In our study, the total effective rate $(C R+P R)$ of patients who received implantation of radioactive ${ }^{125} \mathrm{I}$ seeds was $93.4 \%$, along with 1-, 3-, and 5-year OS rates of $83.35 \%$, $25.57 \%$, and $11.34 \%$, respectively; and a median survival time of 24.8 months. For stage IIIA and IIIB patients, the 5 -year survival rates were $19.63 \%$ and $10.0 \%$, with median survival time of 26.67 and 24.59 months, respectively. Huang [21] has reported 32 patients of stage IIIB NSCLC treated with radical resection and implantation of radioactive ${ }^{125}$ I seeds; their 1 - and 3-year survival rates were $63.8 \%$, and $31.9 \%$, respectively. At present, many studies have reported the significant short-term therapeutic efficacy of radioactive seed implantation for lung cancer, but only a few reports have discussed its long-term therapeutic efficacy; these studies include only a small number of cases. In our study, the significant short-term therapeutic efficacy in our patients may be attributed to the following reasons: 1) we strictly followed the principle of radioactive seeds implantation, i.e., the equidistant principle; 2) the median dose was obviously higher than the effective dose; 3) our prescribed dose was higher than the dose of external beam radiotherapy.

Pneumothorax is the most common complication for lung cancers treated with implantation of CT-guided ${ }^{125} \mathrm{I}$ radioactive seeds, with an incidence rate of 10.0-30.0\% [22].
In our study, $37(14.9 \%)$ patients experienced pneumothorax, which was similar to the previous report. These patients had various forms of emphysema, and fortunately, we were prepared for it. The standard treatment of radiation pneumonitis and the overall incidence occurs in $15-40 \%$ [23]. However, no grade 3-4 pneumonitis was found in this study, which may be related to the short radiation distance of ${ }^{125}$ I seeds.

Although each report on prognostic factors of stage III NSCLC patients is different, most studies show that conventional factors are the main prognostic factors. Langendijk et al. [24] showed, using multivariate analysis, that the pre-treatment hemoglobin level was an independent prognostic factor for both loco-regional control and overall survival in patients with inoperable NSCLC treated with definitive radiotherapy. Our results showed that the 1-, 3-, and 5-year survival rates of 80 patients with pre-treatment hemoglobin levels $<120 \mathrm{~g} / 1$ were lower than those of the 102 patients whose pre-treatment hemoglobin levels were $\geq 120 \mathrm{~g} / 1$ (Table 1). Further, in the multivariate analysis, pre-treatment hemoglobin level was an independent prognostic factor. The reason behind the better prognosis of the higher pre-treatment hemoglobin group may be that radio sensitivity is higher when sufficient oxygen is supplied; thus, the same radiological dose can eliminate more cancerous cells. These results are consistent with the clinical phenomenon that anemia can occur in patients after receiving radiotherapy. Durmus et al. [25] have concluded that prolonged OS is independently associated with a small total tumor volume (TTV $<80$ vs. $\left.>80 \mathrm{~cm}^{3} ; p=0.01\right)$ in 147 patients with unresectable or medically inoperable NSCLC treated with three-dimensionally planned conformal radiotherapy. We divided all our patients into three groups according to the tumor diameter; the 1-, 3-, and 5-year survival rates were significantly different among these groups. Moreover, multivariate analysis showed that the diameter of the tumor was also an independent prognostic factor. Durmus et al. believe that tumor diameter is associated with the number of tumor stem cells; a higher number of tumor stem cells is associated with more difficult therapy with radioactive seed implantation, leading to lower survival rates. The $\mathrm{D}_{100}$ after treatment divided into three groups ( $\leq 80.0 \mathrm{~Gy}$, 80.0-110.0 Gy, > 110.0 Gy), was also independently associated with prognosis, as the 1-, 3-, and 5-year survival rates were significantly different in these groups. The prognosis of $\mathrm{D}_{100}$ after treatment $(>110.0 \mathrm{~Gy})$ in patients was better and thus, $\mathrm{D}_{100}$ after treatment $(>110.0 \mathrm{~Gy})$ is beneficial for patients with stage III NSCLC. The results of our research suggest that, if the prescribed dose exceeded $110.0 \mathrm{~Gy}$, it would be beneficial for patients with stage III NSCLC. However, further clinical and research investigations are required to confirm this finding.

In conclusion, there are many prognostic factors associated with stage III NSCLC. Pre-treatment hemoglobin, $\mathrm{D}_{100}$, and maximum tumor diameter might be the major prognostic factors in patients with NSCLC treated with radiotherapy. Implantation of radioactive ${ }^{125}$ I seeds could be effective in the treatment of NSCLC; the key point of our clinical study is to combine seed implantation with chemotherapy for each patient with stage III NSCLC. 
Peng Du [26] reported that implantation of radioactive ${ }^{125}$ I seeds is safe for the treatment of NSCLC, with few complications and short-term efficacy. The major complications in their study were pneumothorax and bloody sputum. Hence, more cases should be observed to investigate the long-term therapeutic effects. At present, implantation of radioactive ${ }^{125}$ I seeds for NSCLC is still in its inception; however, it is primarily used for unresectable advanced tumors, with good short-term efficacy and local control rate. Improving positioning techniques and reforming implantable medical devices provide a broader space for further development of implantation of radioactive ${ }^{125}$ I seeds.

\section{Conclusions}

CT-guided ${ }^{125}$ I seed implantation combined with chemotherapy is an effective, minimally invasive method for treating stage III NSCLC. Hemoglobin level before treatment, $\mathrm{D}_{100}$, and the maximum tumor diameter might be major prognostic factors in patients treated with radiotherapy for NSCLC.

\section{Acknowledgements}

Authors are grateful to the Chinese Northern Radioactive Seed Brachytherapy Group for their excellent assistance. This research project was supported by the National Natural Science Foundation of Tianjin (No. 15JCYBJC28400), National Cancer Clinical Medicine Research Center (No. 13ZCZCSY20300), and the National Natural Science Foundation of China (No. 8157102300).

\section{Disclosure}

Authors declare no conflict of interests.

\section{References}

1. Jensen AD, Münter MW, Bischoff $\mathrm{H}$ et al. Treatment of nonsmall cell lung cancer with intensity-modulated radiation therapy in combination with cetuximab: the NEAR protocol (NCT00115518). BMC Cancer 2006; 6: 122.

2. Lemjabbar-Alaoui $\mathrm{H}$, Hassan OU, Yang YW et al. Lung cancer: Biology and treatment options. Biochim Biophys Acta 2015; 1856: 189-210.

3. Mirimanoff RO. Neoadjuvant chemoradiotherapy followed by surgery for stage IIIa and IIIb non-small-cell lung cancer (NSCLC): is it still justified? Chin Clin Oncol 2015; 4: 49.

4. Hurria A, Kris MG. Management of lung cancer in older adults. CA Cancer J Clin 2003; 53: 325-341.

5. Weir HK, Thun MJ, Hankey BF et al. Annual report to the nation on the status of cancer, 1975-2000, featuring the uses of surveillance data for cancer prevention and control. J Natl Cancer Inst 2003; 95: 1276-1299.

6. Huo X, Wang H, Yang J et al. Effectiveness and safety of CT-guided (125) I seed brachytherapy for postoperative locoregional recurrence in patients with non-small cell lung cancer. Brachytherapy 2016; 15: 370-380.

7. Bretschneider T, Ricke J, Gebauer B et al. Image-guided highdose-rate brachytherapy of malignancies in various inner organs technique, indications, and perspectives. J Contemp Brachytherapy 2016; 8: 253-263.

8. Wan XB, Jiang R, Xie FY et al. Endoscope-Guided Interstitial Intensity-Modulated Brachytherapy and Intracavitary
Brachytherapy as Boost Radiation for Primary Early T Stage Nasopharyngeal Carcinoma. PLoS One 2014; 9: e90048.

9. In 't Hout BA, Schenk KE, van der Linden AN et al. Efficacy of localization of non-palpable, invasive breast cancer: Wire localization vs. Iodine-125 seed: A historical comparison. Breast 2016; 29: 8-13.

10. Challapalli A, Jones E, Harvey C et al. High dose rate prostate brachytherapy: an overview of the rationale, experience and emerging applications in the treatment of prostate cancer. $\mathrm{Br}$ J Radiol 2012; 85 (Spec Iss 1): S18-S27.

11. Beyer DC, Priestley JB. Biochemical disease-free survival following I-125 prostate implantation. Int J Radiat Oncol Biol Phys 1997; 37: 559-563.

12. Graham PH, Gebski VJ, Langlands AO. Radical radiotherapy for early non-small cell lung cancer. Int J Radiat Oncol Biol Phys 1995; 31: 261-266.

13. Jeremic B, Classen J, Bamberg M. Radiotherapy alone in technically operable, medically inoperable, early-stage (I/II) nonsmall cell lung cancer. Int J Radiat Oncol Biol Phys 2002; 54: 119-130.

14. Li W, Guan J, Yang L et al. Iodine-125 brachytherapy improved overall survival of patients with inoperable stage III/ IV non-small cell lung cancer versus the conventional radiotherapy. Med Oncol 2015; 32: 395.

15. Nishino M, Jackman DM, Hatabu $\mathrm{H}$ et al. New Response Evaluation Criteria in Solid Tumors (RECIST) Guidelines for Advanced Non-Small Cell Lung Cancer: Comparison with Original RECIST and Impact on Assessment of Tumor Response to Targeted Therapy. AJR Am J Roentgenol 2010; 195: W221-W228.

16. Tyldesley S, Boyd C, Schulze K et al. Estimating the need for radiotherapy for lung cancer: an evidence-based epidemiologic approach. Int J Radiat Oncol Biol Phys 2001; 49: 973-985.

17. Martinez-Monge R, Pagola M, Vivas I et al. CT-guided permanent brachytherapy for patients with medically inoperable early-stage non-small cell lung cancer (NSCLC). Lung Cancer 2008; 61: 209-213.

18. Matsuoka H, Nishio W, Okada $\mathrm{M}$ et al. Resection of chest wall invasion in patients with non-small cell lung cancer. Eur J Cardiothorac Surg 2004; 26: 1200-1204.

19. Wisnivesky JP, Yankelevitz D, Henschke CI. Stage of lung cancer in relation to its size: Part 2. Evidence. Chest 2005; 127: 1136-1139.

20. Mountain CF. Revisions in the international system for staging lung cancer. Chest 1997; 111: 1710-1717.

21. Li W, Zheng Y, Li Y et al. Effectiveness of 125 I seed implantation in the treatment of non-small cell lung cancer during R2 resection. Oncol Lett 2017; 14: 6690-6700.

22. Langendijk H, De Jong J, Wanders R et al. The importance of pre-treatment hemoglobin level in inoperable non-small cell lung carcinoma treated with radical radiotherapy. Radiother Oncol 2003; 67: 321-325.

23. Rodrigues G, Lock M, D'Souza D et al. Prediction of radiation pneumonitis by dose-volume histogram parameters in lung cancer - a systematic review. Radiother Oncol 2004; 71: 127-138.

24. Etiz D, Marks LB, Zhou SM et al. Influence of tumor volume on survival in patients irradiated for non-small cell lung cancer. Int J Radiat Oncol Biol Phys 2002; 53: 835-846.

25. Chai SD. Complication and management of 125 I radioactive seeds implantation for lung cancer. radioactive seeds implantation for chest cancer, TianJin. The Tianjing Science Press 2007; 204.

26. Du P, Xiao Y, Lu W et al. Modified Fan-Shaped Distribution Technology for Computed Tomography (CT)-Guided Radioactive Seed Implantation in Lung Cancer Patients with Lung Dysfunction. Med Sci Monit 2017; 23: 4366-4375. 